Research Paper

\title{
Swainsonine Induces Apoptosis through Mitochondrial Pathway and Caspase Activation in Goat Trophoblasts
}

\author{
Yong Huang\#, Feng Dong\#, Qian Du, Hongling Zhang, Xiaomao Luo, Xiangjun Song, Xiaomin Zhao, \\ Wenlong Zhang, Dewen Tong ${ }^{\bowtie}$ \\ College of Veterinary Medicine, Northwest A\&F University, Yangling, Shaanxi 712100, P.R. China \\ \# These authors contributed equally to this work.
}

$\triangle$ Corresponding author: Dewen Tong. Tel: 0086-29-8709-1622. Fax: 0086-29-8709-1032. E-mail: dwtong@nwsuaf.edu.cn.

( ) Ivyspring International Publisher. This is an open-access article distributed under the terms of the Creative Commons License (http://creativecommons.org/ licenses/by-nc-nd/3.0/). Reproduction is permitted for personal, noncommercial use, provided that the article is in whole, unmodified, and properly cited.

Received: 2014.03.20; Accepted: 2014.06.06; Published: 2014.07.II

\begin{abstract}
The indolizidine alkaloid swainsonine (SW) has been reported to impair placentae and ultimately cause abortion in pregnant goats. Up to now, however, the precise effects of SW on goat trophoblast cells (GTCs) are still unclear. In this study, the cytotoxicity effects of SW on GTCs were detected and evaluated by MTT assay, AO/EB double staining, DNA fragmentation assay and flow cytometry analysis. Results showed that SW treatment significantly suppressed GTCs viability and induced typical apoptotic features in a time- and concentration-dependent manner. SW treatment increased Bax protein levels, reduced $\mathrm{Bcl}-2$ protein levels, induced Bax translocation to mitochondria, and triggered the release of cytochrome $\mathrm{c}$ from mitochondria into cytosol, which in turn activated caspase-9 and caspase-3, and cleaved PARP, resulting in GTCs apoptosis. However, caspase-8 activity and the level of Bid did not exhibit significant changes in the process of SW-induced apoptosis. In addition, TUNEL assay suggested that SW induced GTCs apoptosis but not other cells in goat placenta cotyledons. Taken together, these data suggest that SW selectively induces GTCs apoptosis via the activation of mitochondria-mediated apoptosis pathway in goat placenta cotyledons, which might contribute to placentae impairment and abortion in pregnant goats fed with SW-containing plants. These findings may provide new insights to understand the mechanisms involved in SW-caused goat's abortion.
\end{abstract}

Key words: swainsonine, apoptosis, caspase, mitochondrial pathway, goat trophoblast cells, abortion.

\section{Introduction}

The indolizidine alkaloid swainsonine (SW), a herbal toxin, is the main toxic ingredient in locoweeds (including many Astragalus and Oxytropis plants) [1, 2]. These plants possess a wide range of geographical distribution and seriously threat prairie animal husbandry all over the world $[3,4]$. Previous studies have confirmed that ingestion of SW-containing plants cause tissue damage in several organs and tissues, such as reproductive, nervous, endocrine, and immune systems, particularly in reproductive system [5-7]. Ingestion of SW-containing plants almost affects every aspect of reproduction in livestock, leading to abnormal ovarian function, altered oogenesis, delayed placentation, and even abortion [8-10]. In vivo investigations conducted on pregnant goats have also demonstrated that ingestion of SW-containing plants can induce trophoblasts and luteal cells lesion, retard placental development, and ultimately lead to abortion $[5,6]$. In vitro studies have confirmed that SW can impair cell function of goat luteal cells and induce apoptosis [11]. However, it is still unclear whether SW plays a dominant role in the trophoblast lesion and 
placenta impairment caused by SW-containing plants, as well as the precise effects of SW on trophoblasts and placenta cotyledons.

Apoptosis is a kind of pattern of cell death during various physiological and pathological conditions, including embryogenesis, placentation, immune response, cells homeostasis, inflammation and cancers $[12,13]$. Apoptosis induced by physiological stimuli is present in trophoblast cells throughout gestation, and is believed to be physiologically important for normal placental development and fetal growth, whereas apoptosis disorder is associated with some obstetrical complications [14-17]. Some physiological stimuli (such as cytokines and growth factors) or non-physiological stimuli (such as T-2 Toxin, some anticancer drugs, and lipopolysaccharide) may induce or inhibit the apoptotic process of trophoblasts [17, 18]. Previous study demonstrates that trophoblast apoptosis is greatly intensified in cases of spontaneous abortion [19], while toxic stimuli promote apoptosis process and cause pathological abortion [20,21]. The apoptotic effects of some toxicological compounds on trophoblast cells are responsible for trophoblast lesion and abortion occurrence [20, 21]. These findings hint us that SW may induce GTCs apoptosis and responsible for SW-caused goat's abortion. However, the roles of SW in induction of pathological processes and relative molecular mechanisms are still unclear.

In the present study, we investigated the cytotoxicity effects of SW on goat trophoblast cells, and detected its apoptosis-inducing effects at both cell and tissue levels, so as to illuminate the possible mechanisms involved in SW-caused goat's abortion.

\section{Materials and methods}

\section{Materials}

The SW used in this study was extracted from Oxytropis kansuensis Bunge and characterized in our laboratory according to the published protocol [22]. Its purity was up to $99 \%$. SW was dissolved in phosphate buffered saline (PBS, $0.01 \mathrm{~mol} / \mathrm{L}, \mathrm{pH} 7.2$ ) at 10 $\mathrm{mg} / \mathrm{mL}$ as stock solution, and stored at $-20{ }^{\circ} \mathrm{C}$ after sterile filtration.

Antibodies against caspase-8, caspase-9, caspase-3, PARP, Bid, Bcl-2, Bax, cytochrome c, COX IV and $\beta$-actin were purchased from Santa Cruz Biotechnology (Santa Cruz, CA, USA). Horseradish peroxidase (HRP)-conjugated secondary antibody was purchased from Wuhan Boster Bio-Engineering (Wuhan, China). Caspase-8 inhibitor (z-IETD-fmk), caspase-9 inhibitor (z-LEHD-fmk) and caspase-3 inhibitor (z-DEVD-fmk) were all purchased from Sigma-Aldrich (St. Louis, MO, US). TUNEL BrightRed Apoptosis Detection Kit was purchased from Vazyme (NJ, USA). All of other chemicals and reagents were the highest quality and obtained from standard commercial sources.

Primary GTCs were obtained according to our previous study [23], and cultured in complete DMEM/F12 culture medium supplemented with $10 \%$ FBS, $100 \mathrm{U} / \mathrm{mL}$ of penicillin and $100 \mu \mathrm{g} / \mathrm{mL}$ of streptomycin, at $37{ }^{\circ} \mathrm{C}$ in a $5 \% \mathrm{CO}_{2}$ atmosphere incubator. All animal experiments were carried out in accordance with policy and ethical guidelines.

\section{Cell viability assessment}

The variation of GTCs viability affected by SW was determined by MTT assay. Briefly, GTCs were seeded into 96-well culture plates at a density of $5 \times 10^{3}$ cells per well and grown in complete DMEM/F12 culture medium. After overnight incubation, the cells were treated with $2.4 \mu \mathrm{g} / \mathrm{mL}$ of SW for $0,6,12,24,36$, or $48 \mathrm{hr}$, or treated with different concentrations of SW $(0,0.8,1.6,2.4,3.2$ or $4.0 \mu \mathrm{g} / \mathrm{mL}$ ) for $24 \mathrm{hr}$. MTT (5 $\mathrm{mg} / \mathrm{mL}$ ) was added to each well and incubated at 37 ${ }^{\circ} \mathrm{C}$ for $4 \mathrm{hr}$ and the resulting formazan crystals were dissolved in DMSO. The absorbance was measured by microplate spectrophotometer (Bio-Tek Instruments, Inc., Winooski, US) at $590 \mathrm{~nm}$.

\section{Morphological analysis by AO/EB staining}

GTCs cultured in 96-well plates were treated with $2.4 \mu \mathrm{g} / \mathrm{mL}$ of $\mathrm{SW}$ for the indicated times or treated with different concentrations of SW for $24 \mathrm{hr}$. After indicated treatment times, cells were stained with acridine orange $(\mathrm{AO}, 200 \mu \mathrm{g} / \mathrm{mL}$ ) and ethidium bromide (EB, $200 \mu \mathrm{g} / \mathrm{mL}$ ) for $10 \mathrm{~min}$ and then washed with PBS to remove background staining. After that, cells were observed under a fluorescence microscope (Nikon Inc, Japan).

\section{DNA fragmentation assay}

Both control and SW-treated GTCs were collected and washed with PBS. DNA extraction was performed according to previous studies [24, 25]. After dissolved in TE buffer, DNA was subjected to $2 \%$ agarose gel electrophoresis for DNA fragmentation analysis.

\section{Flow cytometry analysis}

SW-treated GTCs were double stained with Annexin V-FITC/PI and subjected to flow cytometry analysis for detection of apoptosis. Briefly, $5 \times 10^{5}$ SW-treated cells were pelleted, then washed twice with ice-cold PBS and resuspended in $500 \mu \mathrm{L}$ $1 \times$ Annexin $\mathrm{V}$ binding buffer containing $5 \mu \mathrm{L}$ Annexin V-FITC and $5 \mu \mathrm{L}$ PI. After $10 \mathrm{~min}$ of incubation at room temperature, cells were analyzed by flow cytometry (Beckman Coulter, CA. US). 


\section{Caspase activity measurement}

Caspases activities were measured by colorimetric assay kits (BioVision, Inc., Mountain View, California, US), according to the manufacture's recommendations. Briefly, GTCs were harvested and incubated in ice-cold cell lysis buffer for $30 \mathrm{~min}$ on ice. The supernatants were collected and protein concentrations were determined using BCA Protein Assay Reagent (Pierce, Rockford, IL, US). Equivalent amount of proteins for each sample was incubated with interested caspase substrate. After incubation at $37^{\circ} \mathrm{C}$ for 4 $\mathrm{hr}$, the protease activity was determined at $405 \mathrm{~nm}$ with microplate spectrophotometer (Bio-Tek Instruments, Inc., Winooski, US)

\section{Western blot analysis}

GTCs were harvested and washed with ice-cold PBS, then lysed with ice-cold RIPA lysis buffer (Beyotime Inst. Biotech, Beijing, China) with $1 \mathrm{mmol} / \mathrm{L}$ PMSF. Protein concentrations were calculated by BCA assay kits (Pierce). $20 \mu \mathrm{g}$ of total cellular protein was subjected to $12 \%$ SDS-PAGE and transferred to PVDF membranes (Millipore, Atlanta, GA, US). The membranes were blocked with $5 \%$ defatted milk powder at room temperature for $1 \mathrm{hr}$ and then immunoblotting was performed with primary antibodies at $4{ }^{\circ} \mathrm{C}$ overnight, followed by HRP-conjugated secondary antibody at room temperature for $1 \mathrm{hr}$. Following each step, the membranes were washed five times with PBS-T for $3 \mathrm{~min}$. Finally, the blots were developed using the enhanced chemiluminescence (ECL) system (Pierce).

\section{Detection of apoptotic trophobalst cells in SW-treated goat placenta cotyledons}

Normal goat placenta cotyledons (45-60 days of pregnancy) were isolated sterile tactically according our previous study [23], then the cotyledons were minced into about $5 \mathrm{~mm}^{3}$ pieces and incubated in completed DMEM/F12 culture medium supplemented with $2.4 \mu \mathrm{g} / \mathrm{mL}$ of SW for $48 \mathrm{hr}$, followed by

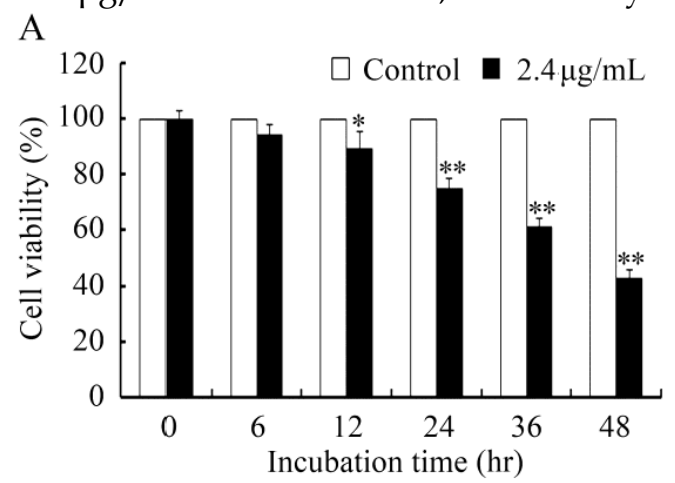

$4 \%$ paraformaldehyde fixation and paraffin-embedding. Cotyledons pieces cultured in completed DMEM/F12 culture medium served as negative control. To assess apoptosis in SW treated goat placenta cotyledons, a TUNEL assay was performed according to the manufacturer's instructions (Vazyme, Piscataway, NJ, USA). In brief, paraffin embedded sections were pretreated with $20 \mu \mathrm{g} / \mathrm{mL}$ proteinase $\mathrm{K}$, underwent antigen retrieval, blocked with $10 \%$ normal goat serum, and then stained for terminal deoxynucleotidyl transferased UTP nick end labeling using a reaction mixture containing tetramethyl rhodamine-dUTP (TMR red-dUTP). GTCs were labeled by immunofluorescence using cytokeratin 7 (CK-7) antibodies according to our previous study [23]. Finally, nuclei were counterstained with DAPI and observed with laser confocal scanning microscopy (A1R/A1, Nikon, Japan).

\section{Statistical analysis}

Data are shown as mean \pm SEM of three independent experiments done in triplicate. Results were analyzed with one-way analysis of variance (ANOVA), and comparisons between treatment groups and control were carried out using the Dunnett's $t$ - test by SPSS 10.0 software. A value of $P<0.05$ was considered significant.

\section{Results}

\section{SW suppresses viability of GTCs}

To determine the cytotoxicity effects of SW on GTCs, we investigated the viability of GTCs after SW treatment using MTT assay. The SW concentrations were inferred according to investigations of direct effects on goat luteal cells [11]. As shown in Fig. 1, treatment with $2.4 \mu \mathrm{g} / \mathrm{mL}$ of SW for $12 \mathrm{hr}$ or 1.6 $\mu \mathrm{g} / \mathrm{mL}$ of SW for $24 \mathrm{hr}$ significantly reduced GTCs viability $(p<0.05)$, and cell viability decreased in a time- and concentration-dependent manner in SW-treated cells.

\section{$\mathrm{B}$}

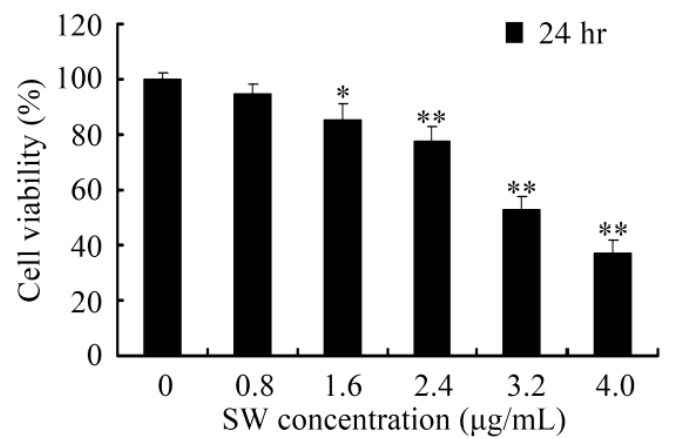

Fig. I. GTCs viability was determined by MTT assay. (A) GTCs were treated with $2.4 \mu \mathrm{g} / \mathrm{mL}$ of SW for indicated times (0-48 hr). (B) GTCs were treated with indicated concentrations $(0-4.0 \mu \mathrm{g} / \mathrm{mL})$ of SW for $24 \mathrm{hr}$. Results were expressed as percent of untreated control cells $(0 \mu \mathrm{g} / \mathrm{mL}$ of SW). The data are mean \pm SEM and mean values of three independent experiments. $* p<0.05, * * p<0.01$ versus the control cells. 
A

$2.4 \mu \mathrm{g} / \mathrm{mL} \mathrm{SW}$

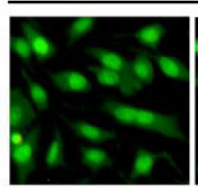

$0 \mathrm{hr}$

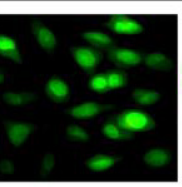

$6 \mathrm{hr}$

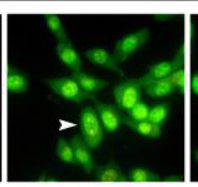

$12 \mathrm{hr}$

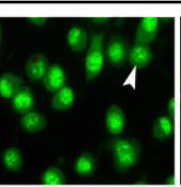

$24 \mathrm{hr}$

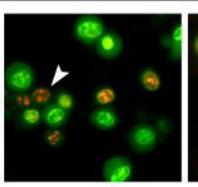

$36 \mathrm{hr}$

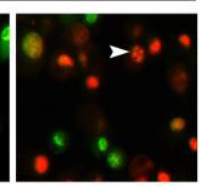

$48 \mathrm{hr}$

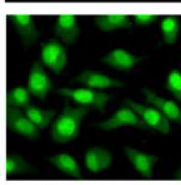

$0 \mu \mathrm{g} / \mathrm{mL}$

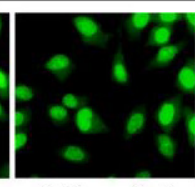

$0.8 \mu \mathrm{g} / \mathrm{mL}$

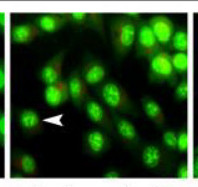

$1.6 \mu \mathrm{g} / \mathrm{mL}$

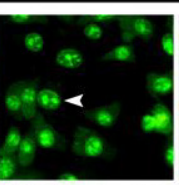

$2.4 \mu \mathrm{g} / \mathrm{mL}$

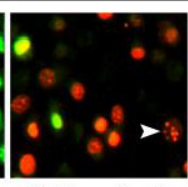

$3.2 \mu \mathrm{g} / \mathrm{mL}$

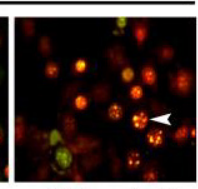

$4.0 \mu \mathrm{g} / \mathrm{mL}$

B

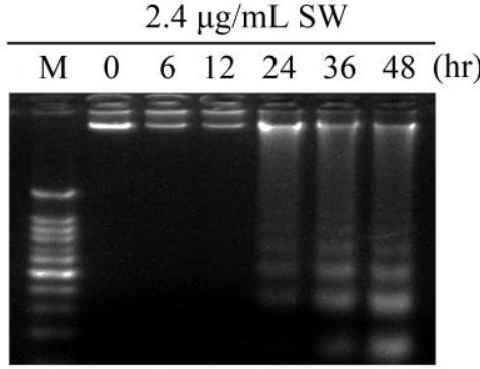

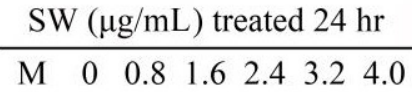
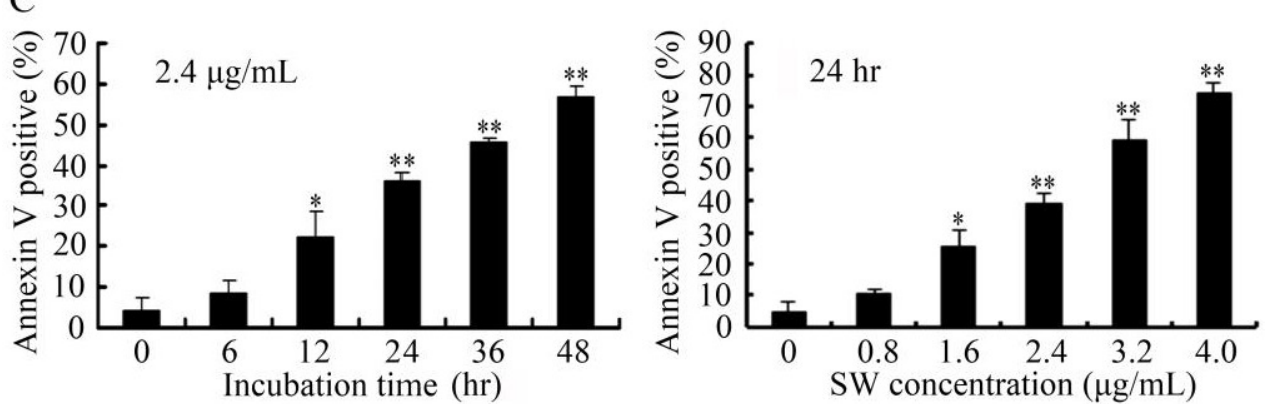

Fig. 2. SW treatment induced GTCs apoptosis. (A) Morphological changes under fluorescence microscopy after AO/EB staining. Normal and early apoptotic cells were stained by $A O$ and showed green fluorescence, while late apoptotic cells were stained by EB and showed red fluorescence. Arrows indicate condensed chromatin and nuclear fragmentation. Data shown are representative for three independent experiments. (B) SW induced DNA fragmentation in GTCs. DNA isolated from SW-treated cells was subjected to $2 \%$ agarose gel electrophoresis, followed by visualization of bands and photography. Data shown are representative for three independent experiments. (C) Flow cytometry analysis of SW induced apoptosis. The Annexin V-staining cells represent total apoptosis cells. The results are mean \pm SEM and mean values of three independent experiments. $* p<0.05, * * p<0.01$ versus the $0 \mathrm{hr}$ cells or $0 \mu \mathrm{g} / \mathrm{mL}$ of $\mathrm{SW}$ treated cells.

\section{SW induces apoptosis in GTCs}

Since cell viability reduction appeared in the MTT assay, we further detected the possible of apoptosis occurrence in SW-treated GTCs using AO/EB double staining, DNA fragmentation assay and flow cytometry after treatment with $2.4 \mu \mathrm{g} / \mathrm{mL}$ of SW for indicated times or various concentrations of SW for 24 hr. GTCs appeared the typical apoptosis features, such as obvious chromatin condensation and slight nuclear fragmentation, at $12 \mathrm{hr}$ after $2.4 \mu \mathrm{g} / \mathrm{mL}$ of SW treatment or $24 \mathrm{hr}$ after $1.6 \mathrm{\mu g} / \mathrm{mL}$ of SW treatment (stained by $\mathrm{AO}$, green) (Fig. 2A). Increasing with $\mathrm{SW}$ treatment times and concentrations, apoptotic cells with typical nuclear fragmentation (stained by EB, red) were increased, whereas the control cells did not appear significant changes in cell nuclei and cell membrane integrity (Fig. 2A).
Besides the morphological changes of apoptosis in SW-treated GTCs, DNA fragmentation assay also showed that characteristic ladder patterns appeared in GTCs after $2.4 \mu \mathrm{g} / \mathrm{mL}$ of SW treatment for $24 \mathrm{hr}$, and were more evident with the increasing of SW treatment times and concentrations (Fig. 2B). The SW-induced apoptosis was further quantified by flow cytometry using Annexin V/PI double staining. The Annexin V stain assay, an event typically associated with apoptosis, was used to evaluate phosphatidylserine externalization from the inner to the outer lipid layer of the plasma membrane [26]. When the cells were treated with $2.4 \mu \mathrm{g} / \mathrm{mL}$ of SW for indicated times (0-48 hr), the average proportion of Annexin V-staining positive cells (total apoptosis cells) significantly increased from $12 \mathrm{hr}$, and reached about $56.8 \%$ at $48 \mathrm{hr}$ (Fig. 2C, left panel). When GTCs were treated 
with different concentrations of SW for $24 \mathrm{hr}$, the average proportion of Annexin $\mathrm{V}$-staining positive cells increased from $4.7 \%$ of the control to $74.3 \%$ (Fig. 2C, right panel). Taken together, these results demonstrated that SW induced GTCs apoptosis in a timeand concentration-dependent manner.

\section{SW-induced apoptosis depends on the activation of caspase- 9 and caspase-3, but not caspase-8}

Caspases are the central components in the execution of apoptosis. Generally, caspases involved in apoptosis are divided into the initiator caspases and the executioner caspases. Caspase- 8 and -9 are the initiator caspases in the death receptor pathway and the mitochondrial pathway, respectively. Caspase-3, downstream caspase of caspase- 8 and -9 , is the key executioner caspase in apoptosis pathway $[27,28]$. To determine which caspase molecules are involved in SW-induced apoptosis, we measured the activities of caspase-8, -9, and -3 in SW-treated GTCs using the colorimetric assay kits. Compared with the untreated control cells, SW treatment significantly induced the activation of caspases- 9 and -3 , but did not induce the activation of caspase- 8 during the treated period (Fig. 3A). Western blot analysis showed that full-length procaspase-9 and procaspase- 3 decreased with the increased treated times, while their cleaved form increased (Fig. 3B). However, the cleavage of procaspase-8 was not observed in this experiment (Fig. 3B). PARP, an indicator of caspase- 3 activation during apoptosis [29], was appeared to be cleaved obviously after $2.4 \mu \mathrm{g} / \mathrm{mL}$ of SW treatment for $12 \mathrm{hr}$ (Fig. 3B).

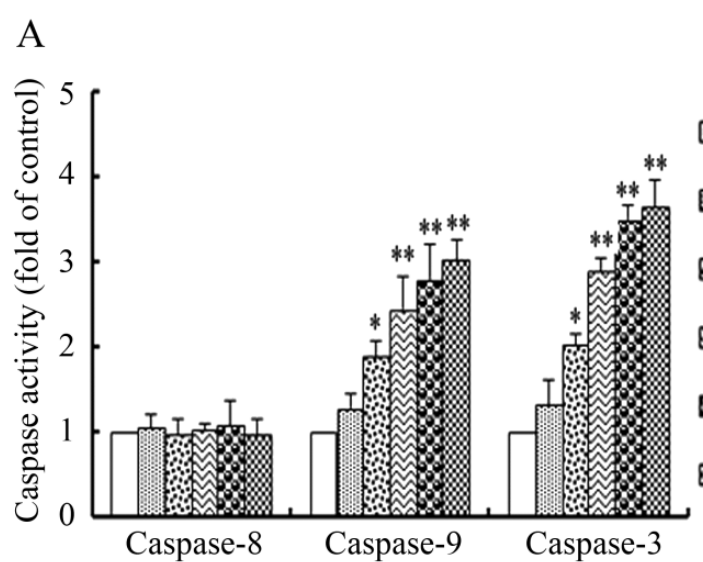

$\mathrm{C}$

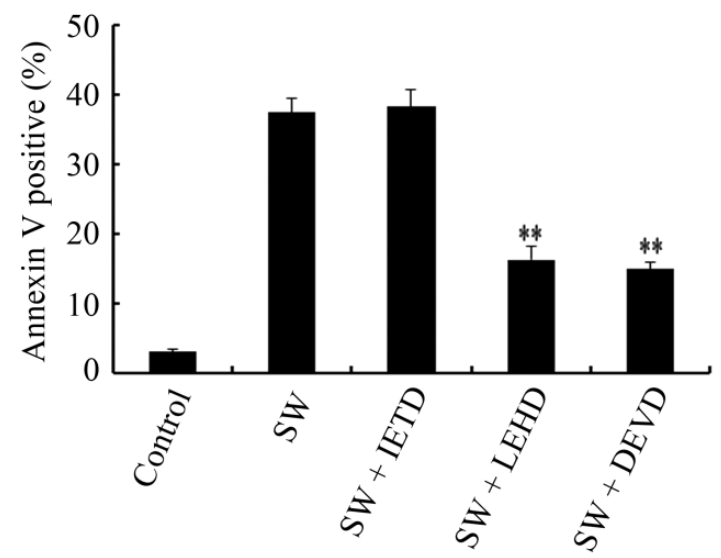

$\mathrm{B}$

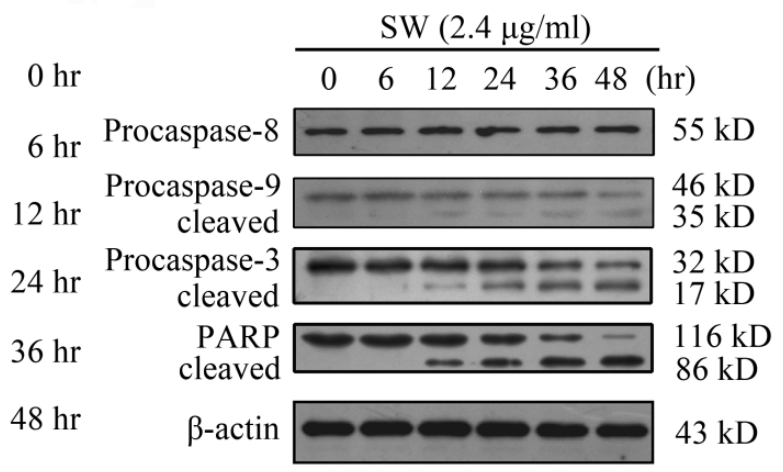

$\mathrm{D}$

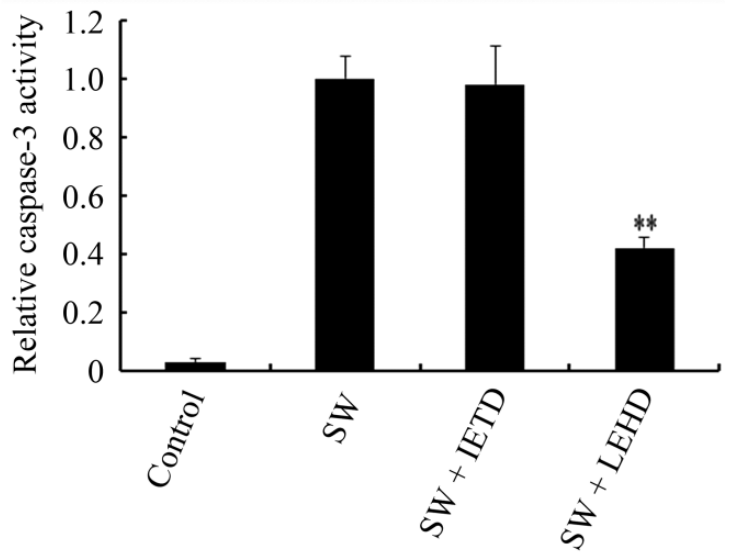

Fig. 3. Effects of SW treatment on caspases activation and PARP cleavage in GTCs. (A) Caspase activities in SW treated GTCs. The lysates of $2.4 \mu g / m L$ of SW treated cells for indicated times were adjusted to equal protein amounts using the BCA assay and the enzymatic activities of caspases $-8,-9$, and -3 were measured using the colorimetric assay kits. The results are mean \pm SEM and mean values of three independent experiments. $* p<0.05, * * p<0.01$ versus the respective control group (0 hr). (B) GTCs were treated with $2.4 \mu \mathrm{g} / \mathrm{mL}$ of SW for indicated times, then lysed and subjected to western blot analysis to detect total and activated caspase-8, $-9,-3$ and PARP. The data shown are representative for three independent experiments. (C) Effects of caspase inhibitors on SW-induced GTCs apoptosis. GTCs were incubated with $20 \mu$ mol/L of caspase inhibitors for 2 hr prior to $2.4 \mu \mathrm{g} / \mathrm{mL}$ of SW treatment for $24 \mathrm{hr}$. $* * p<0.01$ versus the SW-treated cells without inhibitors. The data shown are mean \pm SEM and mean values of three independent experiments. (D) Effects of caspase inhibitors on SW-induced caspase-3 activation in GTCs. GTCs were incubated with $20 \mu \mathrm{mol} / \mathrm{L}$ of caspase inhibitors for $2 \mathrm{hr}$ prior to $2.4 \mu \mathrm{g} / \mathrm{mL}$ of SW treatment for $24 \mathrm{hr}$. The results are mean \pm SEM and mean values of three independent experiments. $* * p<0.01$ versus the SW-treated cells without inhibitors. 
To further confirm the contributions of caspase-8, -9 and -3 in SW-induced apoptosis, we examined apoptosis rates in the SW-treated GTCs pre-treated with or without $\mathrm{z}$-IETD-fmk (caspase-8 specific inhibitor), z-LEHD-fmk (caspase-9 specific inhibitor) and z-DEVD-fmk (caspase-3 specific inhibitor), respectively. As show in Fig. 3C, caspase-9 and caspase-3 specific inhibitors significantly blocked SW-induced apoptosis, while caspase- 8 specific inhibitor did not show such inhibitory effect. Moreover, we determined the roles of caspase- 8 and caspase- 9 in caspase- 3 activation in SW-treated GTCs. As show in Fig. 3D, the activity of caspase-3 was significantly inhibited in SW-treated GTCs in the presence of caspase- 9 specific inhibitor, but not in the presence of caspase- 8 specific inhibitor. These results suggest that SW-induced apoptosis depends on the activation of caspase- 9 and caspase-3, but not caspase-8.

\section{SW induces Bax translocation and cytochrome c release in apoptotic GTCs}

It is known that activated caspase- 8 can cleave Bid (a BH3 only pro-apoptotic protein) to truncated Bid (tBid), then tBid translocates to mitochondria to induce the activation of the mitochondrial pathway [28]. In accordance with the results of caspase- 8 in this study, the levels of Bid did not show significant variations after SW treatment (Fig. 4A), suggesting that the activation of mitochondrial pathway is independent of the activation of caspase- 8 and Bid.
Mitochondria play a vital role in apoptosis triggered by chemical agents [30, 31]. Mitochondrial membrane integrity is regulated by pro-apoptotic and anti-apoptotic members of the Bcl-2 family such as Bcl-2 (anti-apoptotic) and Bax (pro-apoptotic). Anti-apoptotic members protect cells from the induction of apoptosis by interacting with pro-apoptotic members, thus blocking the release of cytochrome c from the mitochondria to cytosol. The imbalance between pro-apoptotic and anti-apoptotic members of the Bcl-2 family determines the ultimate fate of cells [32]. To determine the effects of SW on Bcl-2 family members, we examined Bcl-2 and Bax levels in SW-treated GTCs by western blot. As shown in Fig. 4A, SW treatment induced an increased Bax expression and decreased Bcl-2 expression in a time-dependent manner in GTCs, resulting in an increased ratio of Bax/Bcl-2 (Fig. 4B), which incline to the activation of the mitochondrial pathway. Next we analyzed the translocation of Bax and cytochrome c in SW-treated GTCs. Translocation of Bax from cytosol to mitochondria was observed at $12 \mathrm{hr}$ post-treatment, while translocation of cytochrome $\mathrm{c}$ from mitochondria to cytosol was observed at $12 \mathrm{hr}$ post-treatment (Fig. 4C). Consistent with this, a time-dependent decrease in cytosol Bax and in mitochondrial cytochrome c were also observed (Fig. 4C). These results suggest that SW treatment induces apoptosis in GTCs via activation of mitochondrial pathway.
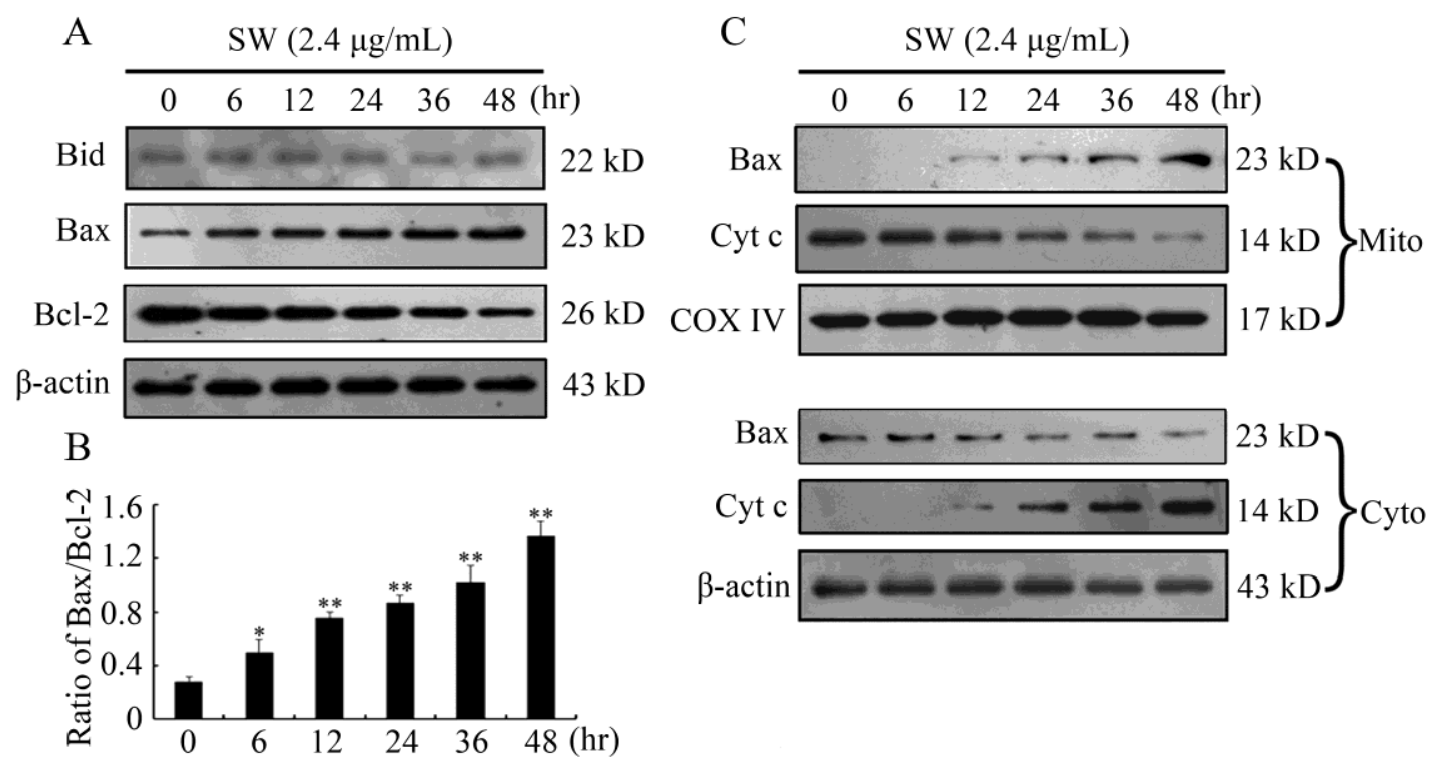

Fig. 4. SW induced GTCs apoptosis via activation of mitochondrial pathway. (A, B) SW treatment did not promote the cleavage of Bid, but increased the ratio of Bax/Bcl-2. The values were calculated from the bands corresponding to Bax and Bcl-2 that normalized to $\beta$-actin. (C) SW treatment induced Bax translocation and cytochrome $\mathrm{c}$ release. GTCs were treated with $2.4 \mu \mathrm{g} / \mathrm{mL}$ of SW for the indicated times. The cytosolic and mitochondrial fraction proteins were collected and then detected by western blot. COX IV and $\beta$-actin were used as internal controls for the mitochondrial fractions and the cytosolic fraction, respectively. All the data shown are representative for three independent experiments. 


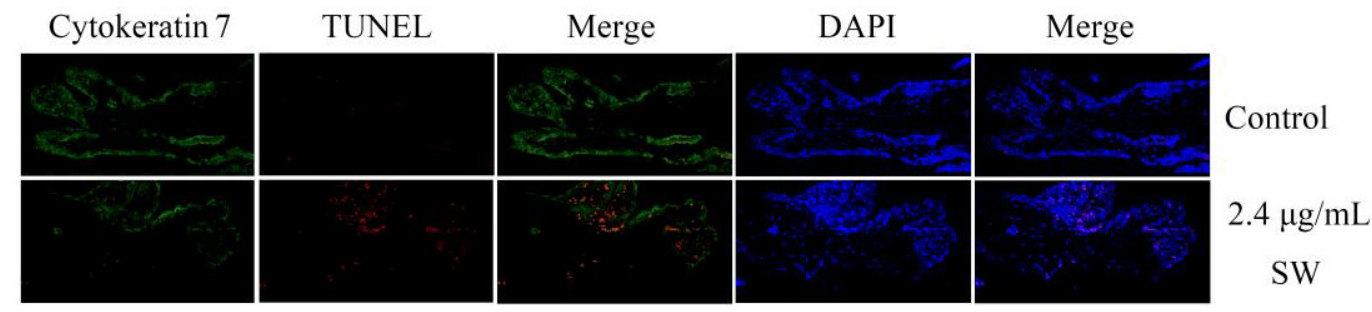

Fig. 5. Detection of apoptotic GTCs in SW-treated goat placenta cotyledons by TUNEL assay. GTCs were labeled with cytokeratin 7 antibody (green) and all cells were stained with DAPI (blue). Merged images showed TUNEL positive (red) cells primarily occurred on GTCs of SW-treated goat placenta cotyledons (200x). The data are representative for three independent experiments.

\section{SW induces GTCs but not CK-7 negative cells apoptosis in goat placenta cotyledons}

To further determine the effects of SW treatment on trophoblast cells and other types of cells in goat placenta cotyledon tissue, normal goat placenta cotyledons were isolated and treated with SW as indicated. Cytokeratin 7 (CK-7), a specific intracellular marker for trophoblasts [33], was used to distinguish GTCs from other types of cells in placental tissue in this experiment. Isolated goat placenta cotyledons were stained with immunofluorescence-coupled CK-7 antibodies and TUNEL kits. Confocal observation clearly showed that TMR red-dUTP positive signals (marked apoptotic cells) almost occurred on CK-7 positive cells (green) in SW-treated cotyledons tissue, and apoptotic GTCs were distinctly increased compared with the control group (Fig. 5), suggesting that SW treatment mainly induces apoptosis in GTCs but not in CK-7 negative cells in goat placenta cotyledons.

\section{Discussion}

$\mathrm{SW}$ is the main toxic ingredient in species of locoweeds that cause loco disease (locoism) [10]. Previous animal studies have showed that long-term ingestion of SW-containing plants causes lesion of trophoblasts and impairs histological structure of placentae $[5,6]$. This study further provides new evidences that SW can directly suppress viability of GTCs, and induce apoptosis of GTCs in both cell and tissue levels.

In previous animal studies, pathological observations showed that GTCs exhibited cellular shrinkage, chromatin condensation and mitochondrial swelling in experimental goats after continuous feeding with SW-containing plants (Oxytropis plants, $10 \mathrm{~g} / \mathrm{kg} /$ body weight/day) over 10 days [5]. Whereas the control goats fed with green hay did not exhibit any clinical symptoms of locoism and can produce healthy lambs [5]. In this study, we found that SW selectively induced GTCs but not CK-7 negative cells apoptosis in goat placenta cotyledons by TUNEL assay, suggesting that GTCs was the most sensitive component to SW in goat placentae. In cell level, we observed that SW suppressed cell viability and induced GTCs apoptosis with the typical morphological characteristics including cellular shrinkage, chromatin condensation, DNA fragmentation, as well as phosphatidylserine externalization, which were partly in consistent with the morphological changes found in the goats fed with Oxytropis plants. These results suggest that SW may serve as an apoptosis inducer at both tissue and cell levels to induce trophoblast cell apoptosis and lead to placentae impairment in pregnant goats fed with SW-containing plants. In addition, SW also acts as an inhibitor of several mannosidases in cells, can interfere with the processing of oligosaccharides and eventually result in cell death [34, 35]. Whether there is some relationship between apoptosis inducing effect and mannosidases inhibiting effect of SW is puzzled and need to be further investigated in future study.

Trophoblast cells play a very important role in maternal recognition of pregnancy and function as predominant cells in nutrient exchange and hormone secretion [36]. Trophoblasts lesion would result in poor invasion and cause some obstetric complications including fetal growth restriction, preeclampsia and even abortion [37, 38]. In miscarriage or spontaneous abortion cases, gene sets of glutathione metabolism and oxidative phosphorylation associated with mitochondrial function are dysregulated in placental villi, which are considered to be a major cause of unexplained miscarriage [39]. In toxicological compounds (such as trichothecene mycotoxins and tetrachlorodibenzo-p-dioxin, TCDD)-induced abortion cases, oxidative damage and mitochondrial dysfunction are considered to responsible for the apoptosis occurrence in placentae and trophoblasts [40, 41]. In this study, SW induction of mitochondrial dysfunction in trophoblast cells was also considered to responsible for the apoptosis occurrence. In SW-treated GTCs, cytochrome c released from dysfunctional mitochondria into cytosol to form apoptosomes together with apoptotic protease activating factor 1 (Apaf-1) and procaspase- 9 , followed by the activation of caspse- 9 and caspase-3, suggesting that mitochondria-mediated apoptosis pathway is activated upon 


\section{SW treatment.}

Furthermore, the dysregulation of mitochondria integrity associated molecules Bcl-2 (anti-apoptotic protein) and Bax (pro-apoptotic protein) in SW-treated cells further suggest that the activation of mitochondria-mediated apoptosis pathway is the main events in the process of apoptosis occurrence. These results indicate that most of toxicological compounds can induce trophoblast apoptosis and cause placentae impairment by induction of mitochondrial dysfunction, and further confirm that mitochondria as the center of cell metabolism play an essential role in maintaining the normal physiological function of trophoblast cells.

In conclusion, SW selectively triggered goat trophoblast apoptosis via the activation of mitochondrial pathway by affecting of Bcl-2 and Bax expression. The SW-induced goat trophoblast apoptosis might responsible for the development of pregnant goat's abortion. These findings in our study provided new insights into understanding the mechanisms of goat's abortion caused by SW-containing plants.

\section{Abbreviations}

GTCs: goat trophoblast cells; SW: swainsonine; PBS: phosphate buffered saline; PMSF: phenylmethyl sulfonyl fluoride; MTT: 3-(4,5-Dimethylthiazol-2-yl)-2 ,5-diphenyltetrazolium bromide; DMSO: dimethylsulfoxide; PARP: poly-ADP-ribose polymerase; AO: acridine orange; EB: ethidium bromide; CK-7: Cytokeratin 7; TUNEL: TdT mediated dUTP Nick End Labeling.

\section{Acknowledgment}

This work was supported by the National Natural Science Foundation of China (31072108/C1802, 31372401/C1802), the Doctoral Program of Higher Education of China (20110204110014) and the Fundamental Research Funds for the Central Universities (QN2011064, ZD2013009, Z111021103).

\section{Contributors and authorship}

Yong Huang and Feng Dong designed the experiments and interpreted the data and wrote the article. Feng Dong performed the experiments with assistance and advice from Qian Du, Hongling Zhang, Xiaomao Luo, Xiangjun Song, Xiaomin Zhao and Wenlong Zhang. Yong Huang and Dewen Tong revised the manuscript. All authors have read the manuscript and approved to submit it to your journal.

\section{Competing Interests}

The authors have declared that no competing interest exists.

\section{References}

1. Colegate S, Dorling P, Huxtable C. A spectroscopic investigation of swainsonine: an a-mannosidase inhibitor isolated from Swainsona canescens. Aust J Chem. 1979; 32: 2257-64.

2. Molyneux RJ, James LF. Loco intoxication: indolizidine alkaloids of spotted locoweed (Astragalus lentiginosus). Science. 1982; 216: 190-1.

3. Welsh S, Ralphs M, Panter K, Pfister J, James L, Wierenga T. Locoweeds of North America: taxonomy and toxicity. Poisonous plants: global research and solutions. 2007: 20-9.

4. Meng L, Xin L, Bing H. Locoweed poisoning in the native grasslands of China. IJPPR. 2011; 1: 41-6.

5. Ding B, Wang J, Xue D, Jia W, Wang S. A Study on the Pathology of Ovary and Placentome in Dairy Goat by Oxytropis kansuensis Intoxication. Chinese Journal of Veterinary Science. 1995; 15: 27-32.

6. Tang C, Duan D, Cao G, Li S, Xue D. Studies on the abortion of goat caused by Oxytropis Ochrocephala. Journal of Northwest Agricultural University. 1989; 4: 52-6.

7. Stegelmeier B, Molyneux R, Elbein A, James L. The lesions of locoweed (Astragalus mollissimus), swainsonine, and castanospermine in rats. Veterinary Pathology Online. 1995; 32: 289-98.

8. Panter K, James L, Stegelmeier B, Ralphs M, Pfister J. Locoweeds: effects on reproduction in livestock. J Nat Toxins. 1999; 8: 53-62.

9. Graham D, Creamer R, Cook D, Stegelmeier B, Welch K, Pfister J, et al. Solutions to Locoweed Poisoning in New Mexico and the Western United States: Collaborative research between New Mexico State University and the USDA-Agricultural Research Service Poisonous Plant Lab. Rangelands. 2009; 31: 3-8.

10. Cook D, Ralphs M, Welch K, Stegelmeier B. Locoweed poisoning in livestock. Rangelands. 2009; 31: 16-21.

11. Huang Y, Li W, Zhao X, Ding L, Yu G, Dong F, et al. Swainsonine differentially affects steroidogenesis and viability in caprine luteal cells in vitro. Theriogenology. 2013; 80: 41-9.

12. Henson PM, Hume DA. Apoptotic cell removal in development and tissue homeostasis. Trends Immunol. 2006; 27: 244-50.

13. Ghobrial IM, Witzig TE, Adjei AA. Targeting apoptosis pathways in cancer therapy. CA-A Cancer J Clin. 2005; 55: 178-94.

14. Huppertz B, Kadyrov M. Apoptosis and its role in the trophoblast. Am J Obstet Gynecol. 2006; 195: 29-39.

15. Heazell A, Crocker I. Live and let die-regulation of villous trophoblast apoptosis in normal and abnormal pregnancies. Placenta. 2008; 29: 772-83.

16. Huppertz B, Hemmings D, Renaud S, Bulmer J, Dash P, Chamley L. Extravillous trophoblast apoptosis-a workshop report. Placenta. 2005; 26: S46-S8.

17. Straszewski-Chavez SL, Abrahams VM, Mor G. The role of apoptosis in the regulation of trophoblast survival and differentiation during pregnancy. Endocr Rev. 2005; 26: 877-97.

18. Furukawa S, Hayashi S, Usuda K, Abe M, Hagio S, Ogawa I. Toxicological pathology in the rat placenta. J Toxicol Pathol. 2011; 24: 95-111.

19. Kokawa K, Shikone T, Nakano R. Apoptosis in human chorionic villi and decidua during normal embryonic development and spontaneous abortion in the first trimester. Placenta. 1998; 19: 21-6.

20. Ishigami N, Shinozuka J, Katayama K-I, Nakayama H, Doi K. Apoptosis in mouse fetuses from dams exposed to T-2 toxin at different days of gestation. Exp Toxicol Pathol. 2001; 52: 493-501.

21. Sehata S, Kiyosawa N, Atsumi F, Ito K, Yamoto T, Teranishi M, et al. Microarray analysis of T-2 toxin-induced liver, placenta and fetal liver lesions in pregnant rats. Exp Toxicol Pathol. 2005; 57: 15-28.

22. Tong D, Wang J, Mu P, Dong Q, Zhao B, Liu W, et al. Analysis of several serum enzymes and blood urea nitrogen of swainsonine-HSA immunized goats. Anim Feed Sci Tech. 2008; 142: 74-88

23. Dong F, Huang Y, Li W, Zhao X, Zhang W, Du Q, et al. The isolation and characterization of a telomerase immortalized goat trophoblast cell line. Placenta. 2013; 34: 1243-50.

24. Li Z, Huang Y, Dong F, Li W, Ding L, Yu G, et al. Swainsonine promotes apoptosis in human oesophageal squamous cell carcinoma cells in vitro and in vivo through activation of mitochondrial pathway. J Bioscience. 2012; 37: $1005-16$

25. Li Z, Xu X, Huang Y, Ding L, Wang Z, Yu G, et al. Swainsonine activates Mitochondria-mediated apoptotic pathway in human lung cancer A549 cells and retards the growth of lung cancer xenografts. Int J Biol Sci. 2012; 8: 394-405.

26. Van Engeland M, Nieland LJ, Ramaekers FC, Schutte B, Reutelingsperger CP. Annexin $\mathrm{V}$-affinity assay: a review on an apoptosis detection system based on phosphatidylserine exposure. Cytometry. 1998; 31: 1-9.

27. Li J, Yuan J. Caspases in apoptosis and beyond. Oncogene. 2008; 27: 6194-206.

28. Kantari C, Walczak H. Caspase- 8 and bid: caught in the act between death receptors and mitochondria. BBA-Mol Cell Res. 2011; 1813: 558-63.

29. Thornberry NA, Lazebnik Y. Caspases: enemies within. Science. 1998; 281: 1312-6.

30. Xu Y, Ge R, Du J, Xin H, Yi T, Sheng J, et al. Corosolic acid induces apoptosis through mitochondrial pathway and caspases activation in human cervix adenocarcinoma HeLa cells. Cancer lett. 2009; 284: 229-37. 
31. Tong X, Lin S, Fujii M, Hou D-X. Echinocystic acid induces apoptosis in HL-60 cells through mitochondria-mediated death pathway. Cancer lett. 2004; 212: 21-32.

32. Cory S, Huang DC, Adams JM. The Bcl-2 family: roles in cell survival and oncogenesis. Oncogene. 2003; 22: 8590-607.

33. Maldonado-Estrada J, Menu E, Roques P, Barré-Sinoussi F, Chaouat G. Evaluation of Cytokeratin 7 as an accurate intracellular marker with which to assess the purity of human placental villous trophoblast cells by flow cytometry. J Immunol Methods. 2004; 286: 21-34.

34. Tulsiani $\mathrm{D}$, Broquist $\mathrm{H}$, James L, Touster $\mathrm{O}$. The similar effects of swainsonine and locoweed on tissue glycosidases and oligosaccharides of the pig indicate that the alkaloid is the principal toxin responsible for the induction of locoism. Arch Biochem Biophys. 1984; 232: 76-85.

35. Tulsiani D, Broquist $\mathrm{H}$, James $\mathrm{L}$, Touster O. Production of hybrid glycoproteins and accumulation of oligosaccharides in the brain of sheep and pigs administered swainsonine or locoweed. Arch Biochem Biophys. 1988; 264: 607-17.

36. Igwebuike U. Trophoblast cells of ruminant placentas - a minireview. Anim Reprod Sci. 2006; 93: 185-98.

37. Pollheimer J, Knöfler M. The role of the invasive, placental trophoblast in human pregnancy. Wien Med Wochenschr. 2012; 162: 187-90.

38. Kaufmann P, Black S, Huppertz B. Endovascular trophoblast invasion: implications for the pathogenesis of intrauterine growth retardation and preeclampsia. Biol Reprod. 2003; 69: 1-7.

39. Lyu S, Song H, Yoon J, Chin M-U, Sung S, Kim Y, et al. Transcriptional profiling with a pathway-oriented analysis in the placental villi of unexplained miscarriage. Placenta. 2013; 34: 133-40.

40. Doi K, Ishigami N, Sehata S. T-2 toxin-induced toxicity in pregnant mice and rats. Int J Mol Sci. 2008; 9: 2146-58.

41. Chen S, Liao T, Wei Y, Tzeng C, Kao S. Endocrine disruptor, dioxin (TCDD)-induced mitochondrial dysfunction and apoptosis in human trophoblast-like JAR cells. Mol Hum Reprod. 2010; 16: 361-72. 